\title{
Experimental Evaluation of Fixing Equipment for Improving the Efficiency of Modular Unit Systems
}

\author{
Kyoon-Tai Kim*, Nam-Cheon Park \\ Construction Management \& Economy Research Division, Korea Institute of Construction Technology, Ilsan, \\ Korea \\ Email: ${ }^{*}$ ktkim@kict.re.kr
}

Received 12 November 2014; revised 16 December 2014; accepted 26 December 2014

Copyright (C) 2014 by authors and Scientific Research Publishing Inc.

This work is licensed under the Creative Commons Attribution International License (CC BY). http://creativecommons.org/licenses/by/4.0/

(c) (i) Open Access

\begin{abstract}
Modular unit systems provide an eco-friendly advanced construction method that improves productivity and reduces carbon emissions and construction waste. In these systems, the prefabrication ratio of the modules should be high in order to support these eco-friendly features. The purpose of this study was to verify the functionality and driving safety of fixing a modular unit with a high prefabrication ratio to a vehicle for transportation to the site using two novel adapter blocks specially developed for this purpose. When asked to evaluate their performance for this study, the truck drivers selected adaptor block type $B$ as providing the highest convenience and functionality. In real-world driving experiments, maximum loads of $15 \mathrm{kN}$ and $25 \mathrm{kN}$ were measured on adapter block types $A$ and $B$, respectively. Future improvements in the adapter blocks that take the safety ratio and the improved convenience of use into account are confidently expected to contribute to the eco-friendliness and the improved productivity of modular unit systems.
\end{abstract}

\section{Keywords}

Component, Modular Housing, Modular Unit, Modular System, Fixing Equipment, Evaluation

\section{Introduction}

\subsection{Background and Purpose}

Today's construction industry suffers from a number of limitations due to existing construction systems, including stagnation of productivity, excessive carbon emissions and excessive creation of construction waste, among

"Corresponding author.

How to cite this paper: Kim, K.-T. and Park, N.-C. (2014) Experimental Evaluation of Fixing Equipment for Improving the Efficiency of Modular Unit Systems. Journal of Building Construction and Planning Research, 2, 244-254.

http://dx.doi.org/10.4236/jbcpr.2014.24022 
others [1]. Modular unit systems are attracting attention as an eco-friendly advanced construction method that can enable a revolutionary improvement in productivity while carbon emissions and waste material. In this construction method, modular units are created in a factory using rectangular parallelepiped steel structure frames and pre-installing floor slabs, walls, windows, various interior/exterior materials, mechanical equipment, plumbing fixtures and electrical wiring which are then transported and assembled into the finished building on site. As most of the work is done in a controlled indoor environment, the quality is high and the modules are only exposed to potential wind and rain damage during the final transportation and assembly phases [2].

The use of modular unit systems also minimizes the creation of construction waste. It is relatively easy to transfer and reuse the dismantled steel structure frames, unlike in conventional reinforced concrete (RC) construction methods, and also has the advantage of creating less material waste than traditional onsite operations due to the standardization of materials. The environmental load can also be reduced by performing precision work at the factory. Thus, modular unit systems are a more eco-friendly sustainable technology than conventional methods [1].

For modular unit systems, $40 \%$ to $90 \%$ of the work can be completed at the factory with the remaining work done on site. The quantity of construction waste created and the environmental load both decrease as the ratio of work completed at the factory (hereinafter referred to as the prefab ratio) increases, so it is important to raise the prefab ratio by installing walls, windows, interior/exterior materials and various items of equipment at the factory in order to raise the prefab ratio and thus improve the resulting structure's eco-friendliness [3].

An important part of this process is the site [4]. If only the steel frames and floor slabs are manufactured at the factory, in which case the prefab ratio is $50 \%$ or less (Figure 1(a)), the unit module can be transported by fixing it to the vehicle using existing fixing methods such as ropes or fixing belts. However, once walls, windows and even various interior/exterior materials have been installed at the factory, for a prefab ratio of $70 \%-90 \%$ (Figure $1(b)$ ), there is a risk of damaging the new walls and materials if they are fixed using existing methods [5]. Also, workers may dislike performing fixing operations at times because fixing a unit module that looks like a container box of about $3 \mathrm{~m}$ in width, $6 \mathrm{~m}$ in length and $3 \mathrm{~m}$ in height using ropes or belts is very inconvenient. It is therefore necessary to develop a new method that can easily fix and safely transport modular units with a high prefab ratio on vehicles in order to maximize the eco-friendliness of modular unit systems [6].

To address this need, Park et al. [6] developed two possible adapter blocks (types A and B) and simulated their structural safety, but their actual performance has not previously been tested and evaluated experimentally in a real-world setting. The purpose of this study is thus to verify and compare the practicality and functionality of the two proposed adapter blocks for fixing a unit module with high prefab ratio to a transporting vehicle and ensure they can be driven safely to the site. Their utility and convenience for real-world fixing operations are verified by attaching a unit module with a high prefab ratio, including pre-installed interior/exterior materials, to a vehicle using the newly developed adapter blocks and their roadworthiness confirmed by driving the loaded transporting vehicle over a typical road surface. Implementing this type of technology to improve modular units' prefab ratios will provide a useful way to boost the eco-credentials of modular unit systems.

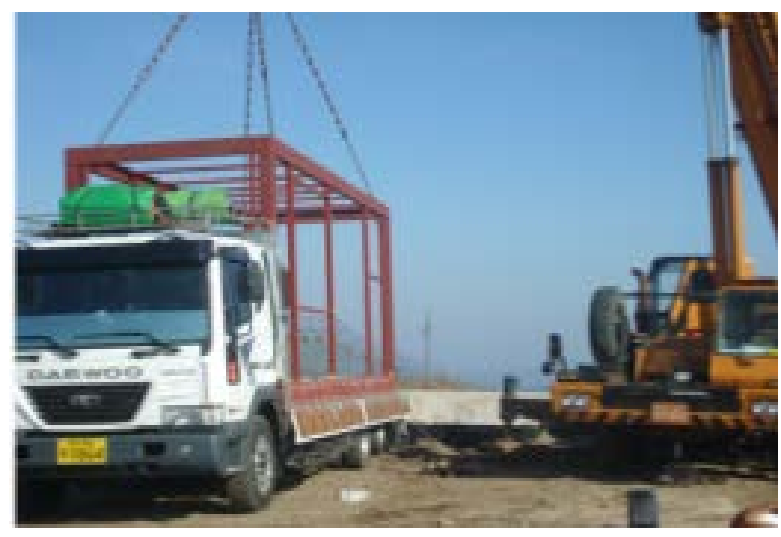

(a)

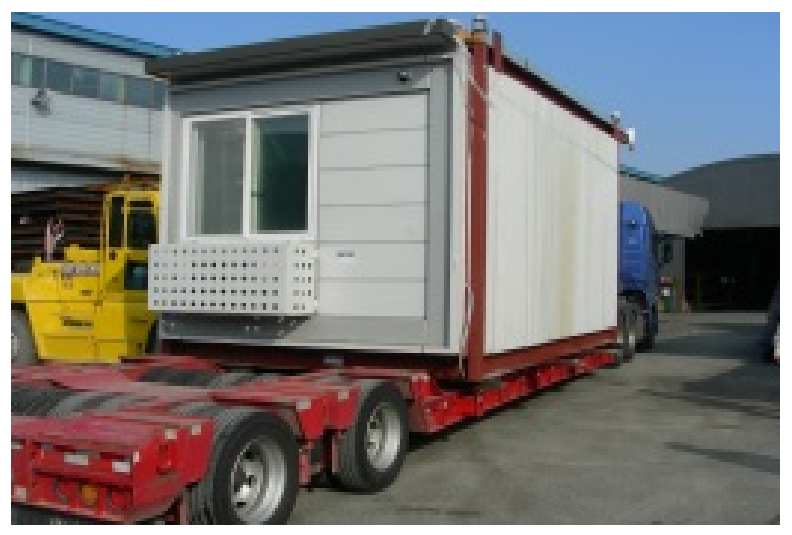

(b)

Figure 1. Unit modules’ prefabrication percentage [6]. (a) 40\% - 50\%; (b) $80 \%$ - 90\%. 


\subsection{Scope and Method}

As noted above, the prefab ratio should be high in order to maximize the eco-friendliness and productivity of a modular unit system. Therefore, this study is designed to facilitate the process of transporting units with pre-attached interior/exterior materials and windows and a prefab ratio of $70 \%$ or higher. The objective of this study is to evaluate the utility and effectiveness of specially designed fixing devices to connect modules to the truck bed. The following tasks were performed for this study:

1) Investigate existing fixing methods, the structure and yield load of the proposed adapter blocks through a review of previous studies;

2) Manufacture the two proposed adapter blocks A and B and predict any potential problems by interviewing an expert in this area;

3) Establish an experimental plan based on the results of the interview to guide the sensor installation, and conduct an experimental evaluation to assess the degree of difficulty of fixing a modular unit to the truck bed with each of the adapter block options in turn and a driving experiment according to the plan developed;

4) Analyse the performance of each of the new adapter blocks.

\section{Status Review of Unit Module Transportation}

\subsection{Methods Currently Utilized to Transport Modular Units}

At present, either 5 ton trucks or 25 ton vibration-free low-bed trailers (hereinafter referred to as trucks) are used to transport modular units to the site in Korea. A forklift or a crane is used to load the unit onto the truck and it is then fixed to the truck bed using chain, rope or a fixing belt in order to transport the unit module safely [7]. A fixing block such as the one shown in Figure 2 is used for such fixing operations. The term "fixing block" refers to the fixing hardware installed and welded by truck owners on an ad hoc basis to make it easier to attach ropes or fixing belts; these fixtures are not pre-installed on the trucks as standard components [6].

\subsection{Adapter Blocks}

The template is used to format your paper and style the text. All margins, column widths, line spaces, and text fonts are prescribed; please do not alter them. You may note peculiarities. For example, the head margin in this template measures proportionately more than is customary. This measurement and others are deliberate, using specifications that anticipate your paper as one part of the entire journals, and not as an independent document. Please do not revise any of the current designations. Adapter block type A connects the modular unit to the truck bed with fixing belts that are attached to connecting holes at the bottom of the square columns on the module with nuts and bolts; the fixing method used by adapter block type B relies on the frictional force created as a result of the fixing belt running through a C-channel along the bottom of the modular unit (Figure 3). Type A is thus relatively inconvenient to install but provides very stable support and type B provides markedly less support but is easy to install [6].

As adapter blocks are connected to the truck bed using the bottom structure of unit module, there is no interference with walls, windows or interior/exterior materials [6]. It should therefore be possible to transport the eco-friendly modules with a high prefab ratio without damage. The new adapter blocks should also avoid the need to modify the existing trucks and modular units by using existing structures such as fixing blocks and holes and C-channels in the modular units [6].

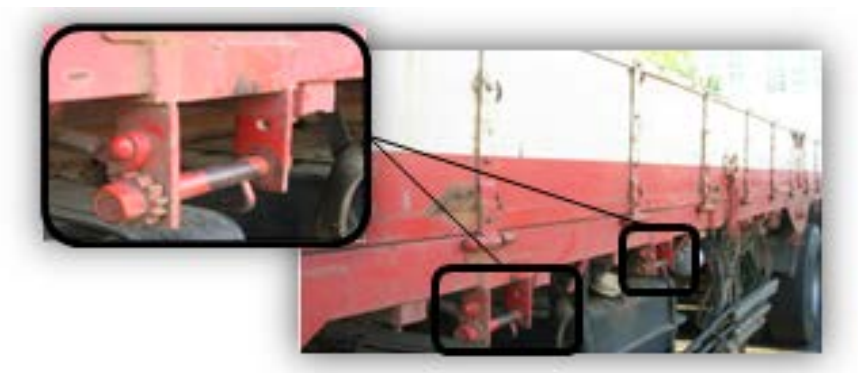

Figure 2. Fixing blocks welded to a truck [6]. 


\subsection{Adapter Block Simulation}

For the analysis of the adapter blocks, lightweight channels and steel plates, the SOLID 186 element consisting of eight panel points, with each panel point having three degrees of freedom, was used. For this study, the elastic modulus was taken to be $206 \mathrm{GPa}$, the tangential modulus $1.45 \mathrm{GPa}$, the yield strength $750 \mathrm{MPa}$, and Poisson's ratio 0.3. Some adapter blocks and modular units with adapter blocks attached were analysed using ANSYS 13.0 without applying a separate pre-processor to perform modelling, mesh generation and finite element analysis. The simulations predicted the yield load of adapter block type A to be approximately $24.6 \mathrm{kN}$ and that for adapter block type B to be about $28.5 \mathrm{kN}$ [6].

\section{Manufacture and Experimental Evaluation of Adapter Blocks}

\subsection{Manufacture}

For this study, four prototypes of each of the two new adapter block types, A and B, were manufactured as shown in Figure 4(a) and Figure 5(a) based on the shop drawings provided in [6] and shown in Figure 4(b) and Figure 5(b).

\subsection{Expert Interviews}

Expert interviews were conducted to discuss the adapter block prototypes manufactured for this study prior to the driving experiment. Opinions were solicited on the design of the new adapter blocks, precautions that should be taken during the experiment and ideas for improving the adapter blocks from expert practitioners who employed at the general manager level at the modular unit factory operated by Company Y. The results of the interviews are summarized below:

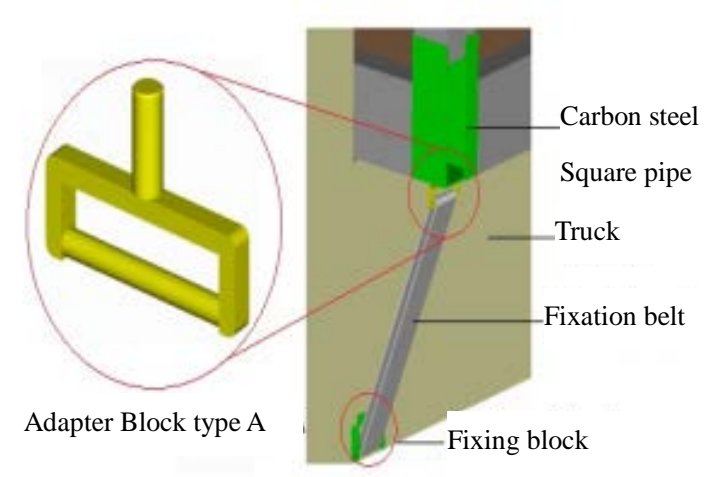

(a)

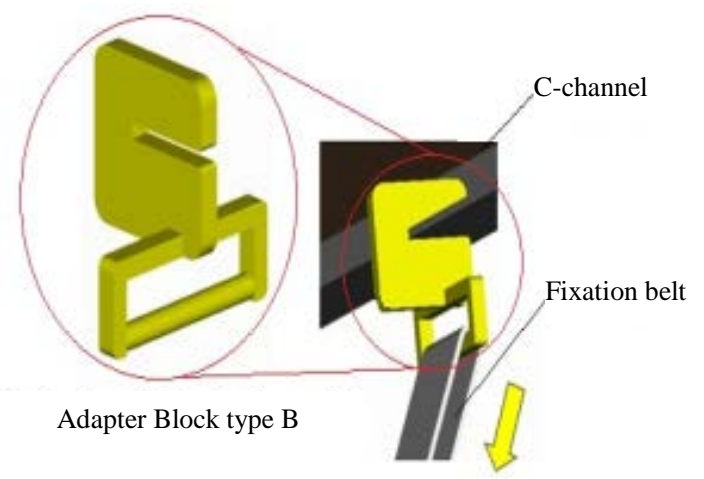

(b)

Figure 3. Fixing mechanism of the proposed adapter blocks [6]. (a) adapt block type A; (b) adapt block type B.

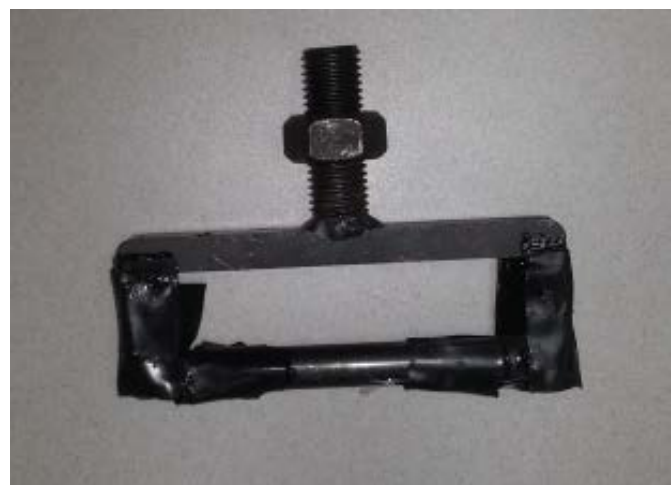

(a)

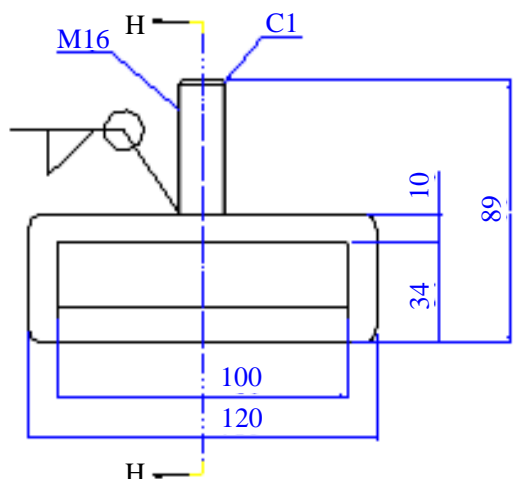

(b)

Figure 4. Adapter block type A. (a) prototype produced; (b) drawing [6]. 


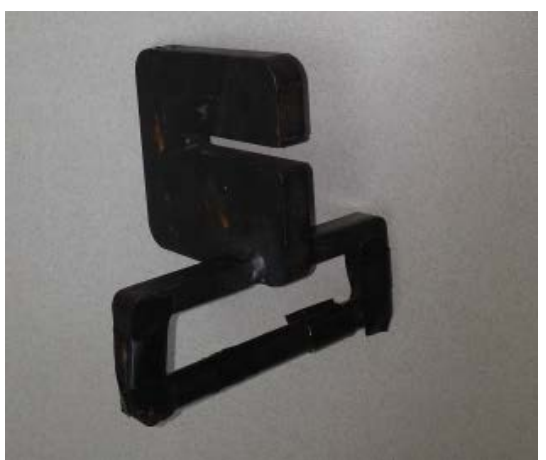

(a)

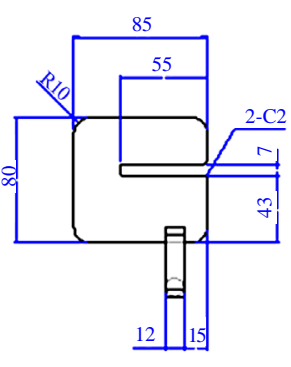

(b)

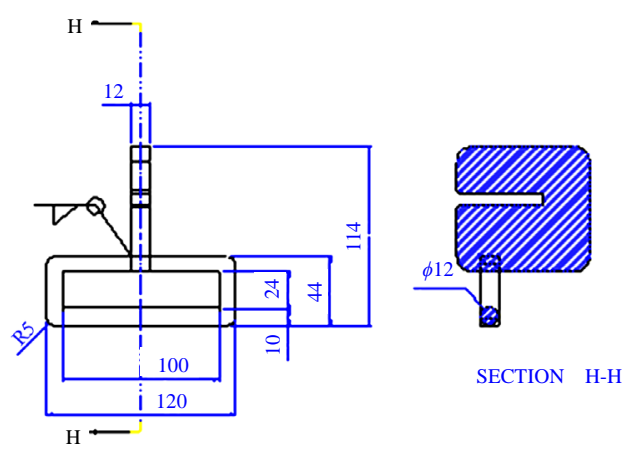

Figure 5. Adapter block type B. (a) prototype produced; (b) drawing [6].

1) The modular unit manufacturers are not generally concerned with potential problems due to the transport fixing device in particular. This is because stable fixation and preventing damage to the modules is considered the responsibility of the truck drivers, as the transportation operations are generally subcontracted.

2) A module with floor slabs, walls and windows, on a frame with dimensions $3200 \mathrm{~mm}(\mathrm{~W}) \times 5800 \mathrm{~mm}(\mathrm{~L})$ $\times 3200 \mathrm{~mm}(\mathrm{H})$ weighs at least 10 tons.

3) In terms of transporting heavy unit modules such as the one described above, adapter block types A and B may not be strong enough. Therefore, it seems that some form of reinforcement would be necessary.

4) If a heavy unit module is to be used as the experimental load, it will be safe to use a vibration-free low-bed trailer as the experimental vehicle for fixation and transport. It would not be advisable to perform the experiment using a 5 ton truck for safety reasons.

5) Since applying two different types of adapter blocks, type A and type B, could lead to confusion, it would be better to develop a single type if possible.

\subsection{Experimental Plan}

Before the expert interviews were conducted, the original plan called for two types of driving experiment: after fixing the modular unit on the truck using four type A adapter blocks and performing the driving experiment, the same procedure would be repeated using four type B adapter blocks after removing the type A adapter blocks. However, this plan was revised to instead perform the experiment by fixing the modular unit with a total of eight adapter blocks, four each of type A and type B, based on the advice of the experts interviewed. The experimental vehicle was also switched from a truck to a low-bed trailer as a result of safety concerns expressed by the interviewees. The experimental test route was selected to be the $7.7 \mathrm{~km}$ between Company Y's factory and Center F located in Gyeonggi-Do [8]. The target section includes a straight line section with an adequate distance for acceleration and incorporates typical road characteristics such as left/right turns, speed bumps, uphill and downhill slopes, crosswalks and U-turns. The preparatory operations for the experiment will be performed in the factory yard of Company Y. The experimental plan is summarized in Table 1.

A strain gage was used for the stress measurement. A total of eight adapter blocks, including four type As and four type Bs, each with a strain gage attached, were prepared as shown in Table 1. A set of four adapters, consisting of two type As and two type Bs, were installed on each side of the low loader truck bed and appropriate sensor symbols assigned [9]. The first character of the sensor symbol indicates type A or B, the second character indicates left or right and the number indicates the sensor number. In the case of AR1 for example, the adapter block is type A, it is attached to the right hand side of the module and the sensor number is 1 . Data was collected from the strain gages at 2 second intervals.

\subsection{Installation of Sensors}

The strain gages used here to monitor the strain experienced by the adapter blocks consist of a resistance wire firmly attached to the sample and connected to an insulated lead wire. The electrical resistance of a material changes if it is subjected to mechanical stress that is sufficient to change the material's dimensions; strain is defined as the ratio of the change in dimensions/the original dimensions. The strain that occurs when a sample is 
Table 1. Experimental plan.

Item

Purpose

Site

Driving Section

Experimental Sequence

Driving Method

Gathering of Data

Recording

Installed Locations
Contents

(1) To examine how convenient it is to install and dismantle the new adapter blocks (qualitative)

(2) To examine the safety of adapter blocks through the driving experiment

About $7.7 \mathrm{~km}$ section of paved road from Company Y's factory to Center F located at H-Si of Gyeonggi-Do
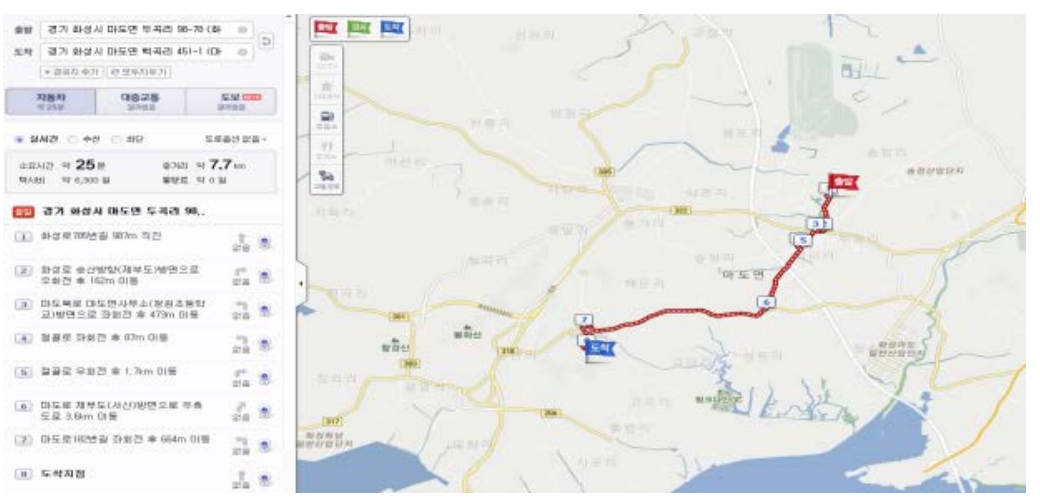

(1) Includes straight line sections of adequate distance to measure acceleration

(2) Includes many left/right turns, speed bumps, uphill and downhill slopes, crosswalks and U-turns

(1) Perform fixing operation using the adapter blocks with sensors installed (factory yard of Company Y)

(2) Stage 1 Drive (Company $\mathrm{Y} \rightarrow$ Center F)

(3) Stage 2 Drive (Center $\mathrm{F} \rightarrow$ Company $\mathrm{Y}$ )

(4) Stage 3 Drive (Company $\mathrm{Y} \rightarrow$ Center F)

(5) Stage 4 Drive (Center $\mathrm{F} \rightarrow$ Company $\mathrm{Y}$ )

(6) Dismantle adapter block (factory yard of Company Y)

(1) Drive regular sections at speeds of $60-80 \mathrm{~km} / \mathrm{h}$

(2) Drive at speeds of $10-30 \mathrm{~km} / \mathrm{h}$ along sections with left/right turns and speed bumps, etc.

(1) Gather data from the strain gage at two second intervals throughout

(1) The person conducting the experiment rides on the truck and notes the location, time and road conditions when taking left/right turns or passing through speed bumps, uphill and downhill slopes, etc. on the map.

(2) After the experiment, the road conditions and change of stress are measured by matching the times of events indicated on the data logger of the strain gage with the corresponding map locations using the data recorded during the experiment.

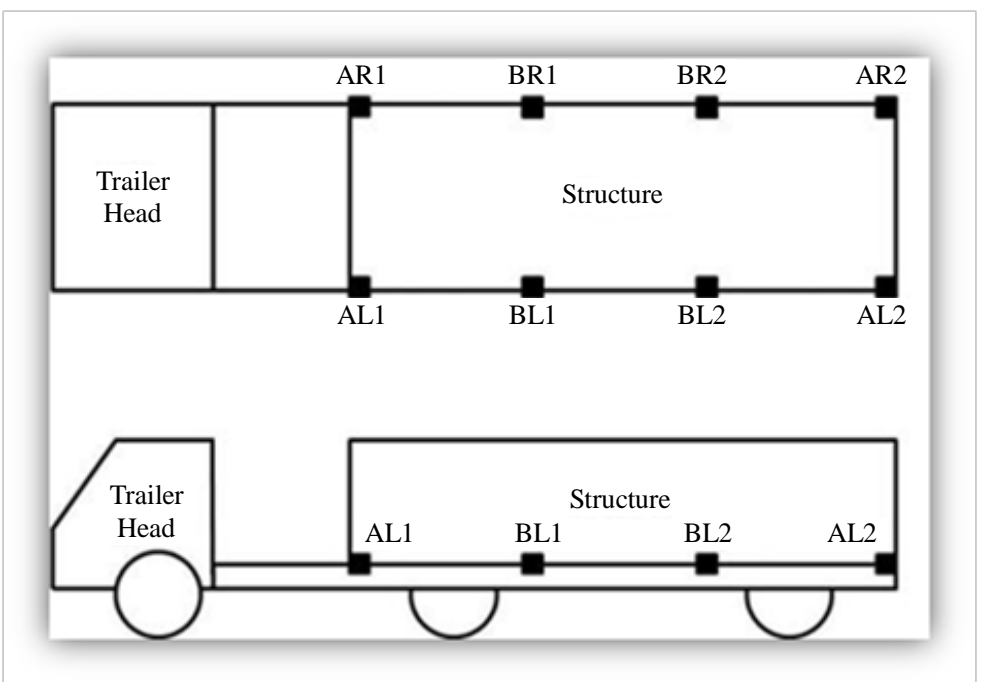


under stress can be measured using a strain gage based on the resulting changes in the resistance of the resistance wire.

A total of four strain gages were installed on each of the eight adapter blocks. The locations selected for the installation are shown in Figure 6(a) and Figure 6(b) and were expected to be the locations where the greatest load would be experienced based on the results of Park et al.'s simulation [6]. Adapter block types A and B with strain gage installed are shown in Figure 6(c) and Figure 6(d).

\subsection{Driving Experiment}

In accordance with the experimental plan, a modular unit was fixed to a low-bed trailer using the adapter blocks with strain gages installed in the factory yard of Company Y. The strain gage data was then collected as the vehicle was driven along the planned route. The driving experiment was performed a total of four times and the strains on the adapter blocks measured every 2 seconds from the start to the end of each run. The driving speed varied during the course of each run; for instance, when passing over a speed bump the vehicle slowed to 10 - 20 $\mathrm{km} / \mathrm{h}$ and when going round a turn was $10-30 \mathrm{~km} / \mathrm{h}$, while it reached speeds as high as $80 \mathrm{~km} / \mathrm{h}$ on the straight sections of road. Figure 7 depicts the various stages of the road test.

For the driving experiment, the researchers rode in the cab of the low-bed trailer and recorded the location, time and road conditions for each road feature, such as left/right turns, speed bumps, or uphill and downhill slopes. These records were then linked to the readings from the data loggers on the strain gages to analyse the changes in the stress experienced by each strain gage for the different driving conditions and events based on the time stamps. Table 2 shows a portion of the results to demonstrate how the road conditions recorded by the researchers were matched to the data logger output.

\section{Performance Review}

\subsection{Convenience of Use}

As this study involved fixing the modular units to the low-bed trailers using the new adapter blocks with multiple strain gages installed, the attached strain gages and wiring inevitably interfered to some extent with the fixing operation. It was also not possible to perform the fixing operation repeatedly because the stability of the sensors had to be protected, making it difficult to achieve a realistic comparison of productivity through an objective analysis of the operation. Therefore, a qualitative analysis of the new method's convenience was instead performed by interviewing the low-bed trailer driver, who had extensive experience with the existing methods used. Although he considered the new adapter blocks to be far more convenient than the existing method of tying the modules to the trailer using ropes or belts, the driver commented that an integrated type of adapter would be preferable because he found it inconvenient to have to deal with two different types of adapter blocks. Of the two blocks tested, the driver preferred type B as type A requires additional fixing tools to fix the nuts and bolts. He also expressed his intention of buying some for his vehicle if a fixing device like type B is developed with verified safety that is convenient to work with becomes commercially available.

\subsection{Safety}

The results of the analysis of the data gathered from stage 1 - stage 4 in the driving experiment are shown below.

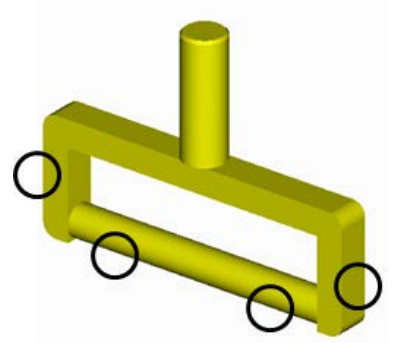

(a)

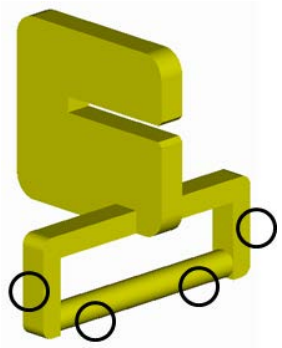

(b)

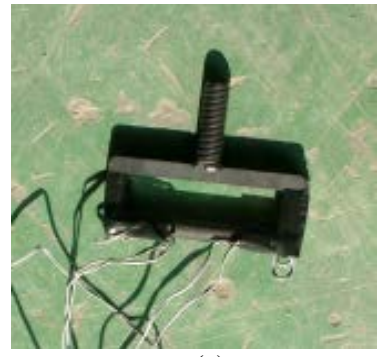

(c)

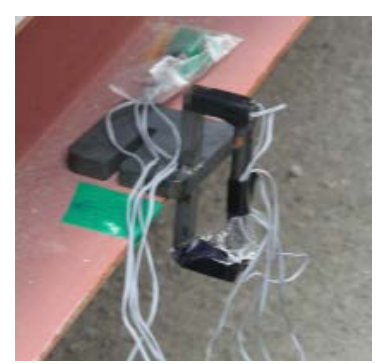

(d)

Figure 6. Installation of strain gage on the adapter blocks (types A and B). (a) installed location of type A; (b) installed location of type B; (c) installed type A; (d) installed type B. 


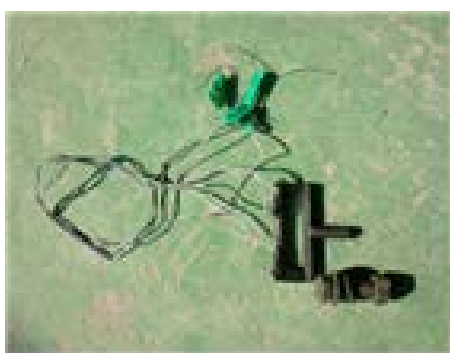

(a)

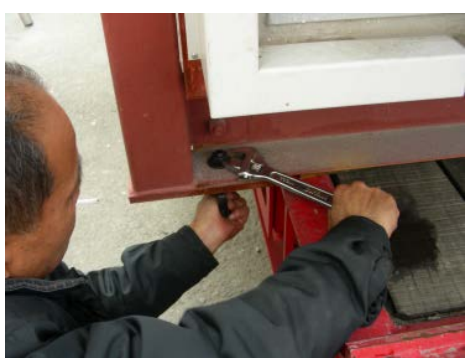

(d)

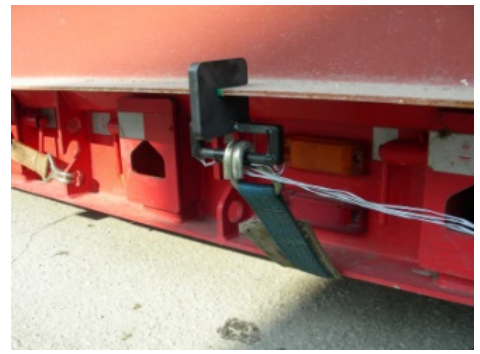

(g)

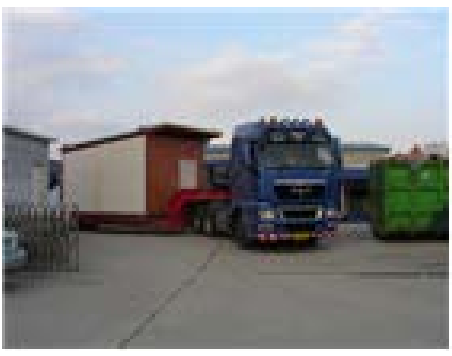

(j)

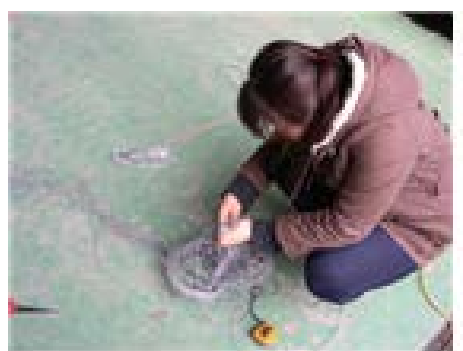

(b)

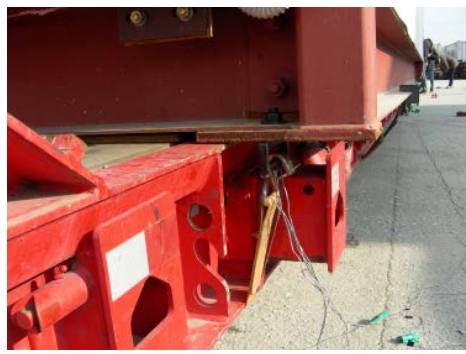

(e)

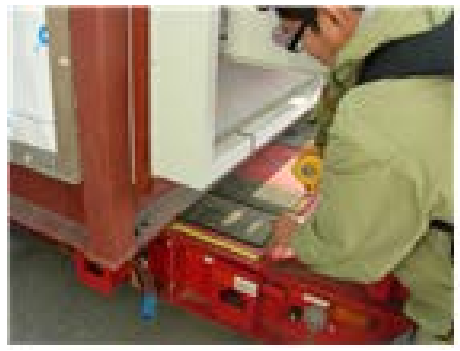

(h)

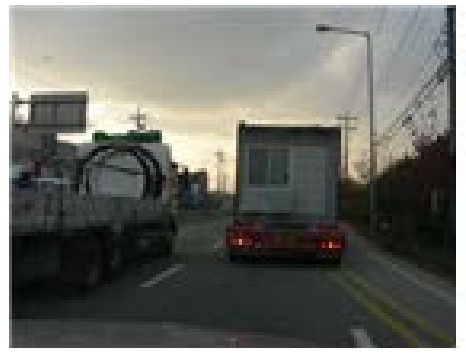

(k)

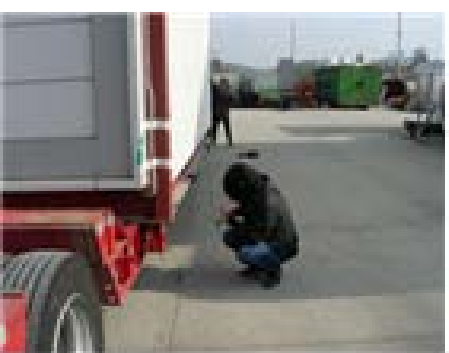

(c)

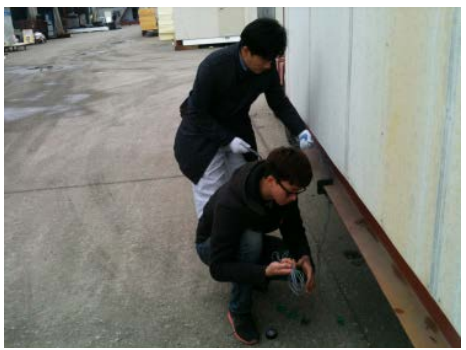

(f)

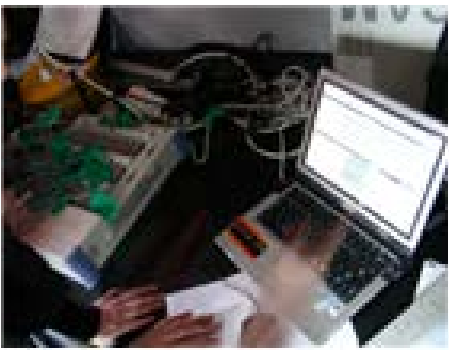

(i)

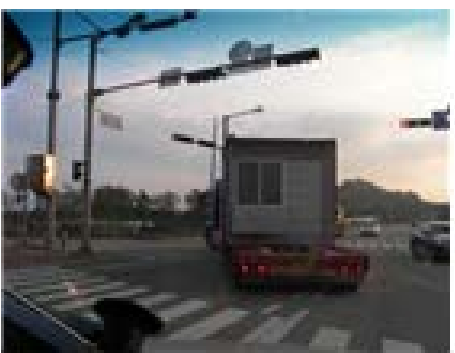

(l)

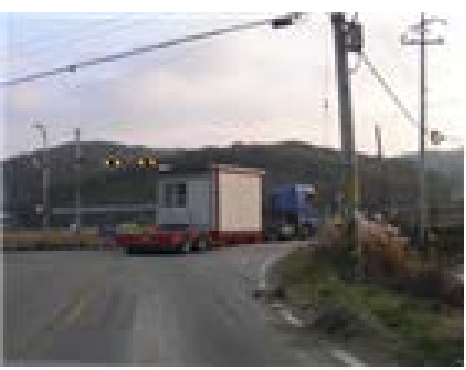

(m)

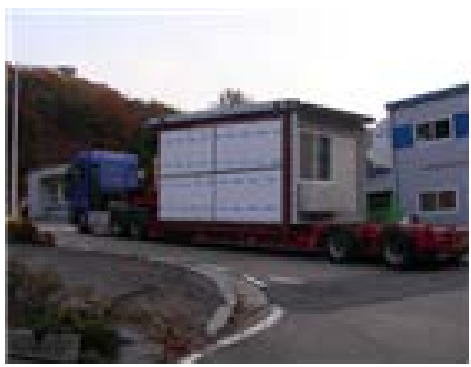

(n)

Figure 7. Performance of sensor installation and driving experiment [10]. (a) installation of strain gage; (b) wiring operation; (c) wiring connection with strain gage; (d) installation of type A; (e) complete installation of type A; (f) installation of type B; (g) complete installation of type B; (h) measurement of installation results; (i) connecting with data logger; (j) complete installation and departure; (k) road navigation; (l) left turn section; (m) right turn section; (n) uphill section. 
Table 2. Sample of data gathered during road tests (from test 1, type A, AR1).

\begin{tabular}{|c|c|c|c|c|c|c|c|c|c|c|}
\hline \multicolumn{4}{|c|}{$\begin{array}{c}\text { Stage } 1 \text { Adapter Block Driving Test } \\
\text { (Y Factory > F Center, Driving Test Distance:7.7 km) }\end{array}$} & \multicolumn{7}{|c|}{ AR1-T1 } \\
\hline \multirow{2}{*}{$\begin{array}{l}\text { Time } \\
\text { (Hr:Min:Sec) }\end{array}$} & \multirow{2}{*}{$\begin{array}{l}\text { Driving } \\
\text { Status }\end{array}$} & \multirow{2}{*}{$\begin{array}{l}\text { Driving Speed } \\
\quad(\mathrm{km} / \mathrm{h})\end{array}$} & \multirow{2}{*}{$\begin{array}{l}\text { Road Condition/ } \\
\text { Location of Vehicle }\end{array}$} & СH000 & СH001 & СH002 & СH003 & \multirow{2}{*}{ average } & \multirow{2}{*}{ strain } & \multirow{2}{*}{$\begin{array}{c}\text { Force } \\
(\mathrm{kN})\end{array}$} \\
\hline & & & & AR1-1 & AR1-2 & AR1-3 & AR1-4 & & & \\
\hline $16: 24: 00$ & Start & 10 & Front gate of Y factory & -9.45 & -6.3 & -5.25 & 6.3 & -3.675 & $-3.7 \mathrm{E}-06$ & -0.0904 \\
\hline $16: 26: 43$ & Left Turn & 10 & & -34.65 & -37.8 & -37.8 & -38.85 & -37.275 & $-3.7 \mathrm{E}-05$ & -0.9170 \\
\hline $16: 27: 38$ & Straight & 20 & & -37.8 & -38.85 & -22.05 & -19.95 & -29.6625 & $-3 E-05$ & -0.7297 \\
\hline $16: 28: 59$ & Slowdown & 10 & Speed Bump & -5.25 & -16.8 & -19.95 & -17.85 & -14.9625 & $-1.5 \mathrm{E}-05$ & -0.3681 \\
\hline $16: 29: 16$ & Slowdown & 10 & Speed Bump & -13.65 & -12.6 & -32.55 & -32.55 & -22.8375 & $-2.3 \mathrm{E}-05$ & -0.5618 \\
\hline $16: 30: 07$ & Slowdown & 10 & Speed Bump & -30.45 & -30.45 & -28.35 & -29.4 & -29.6625 & $-3 \mathrm{E}-05$ & -0.7297 \\
\hline $16: 30: 34$ & Slowdown & 15 & Speed Bump & -26.25 & -21 & -22.05 & -16.8 & -21.525 & $-2.2 \mathrm{E}-05$ & -0.5295 \\
\hline 16:31:36 & Right Turn & 15 & $\begin{array}{l}\text { Right turn to } \mathrm{J} \text { direction } \\
\text { at the } \mathrm{M} \text { intersection }\end{array}$ & -5.25 & -4.2 & -17.85 & -19.95 & -11.8125 & $-1.2 \mathrm{E}-05$ & -0.2906 \\
\hline
\end{tabular}

Each test was driven over the same route, but natural fluctuations in the road traffic conditions resulted in some variation in the vehicle's speed and hence also in the readings recorded for each road feature.

1) Stage 1 Driving Experiment (Test 1 )

Looking at the results of driving test 1, the greatest load was experienced on AR2 and AL2, which were located at the very rear of the module, when the vehicle was stopping, starting and slowing down. The greatest load on AL1 and BL2 occurred during left turns and left cornering, while the greatest on BR1 occurred during right turns. Among the total of 8 adapter blocks, the greatest load of about $15 \mathrm{kN}$ was on BL1 and AR2 during this road test (Figure 8(a)).

2) Stage 2 Driving Experiment (Test 2)

In test 2, the greatest load was experienced by AR2, AL2 and BL1, which were located at the very rear of the modular unit, in the uphill, downhill, stop, restart and speed bump segments of the road test. Here, the greatest load of about $25 \mathrm{kN}$ was recorded for BL1 in this run (Figure 8(b)).

3) Stage 3 Driving Experiment (Test 3)

The results for test 3 revealed that the greatest load was experienced on BR1, BR2 and AL2. As before, this was for the stop, restart, uphill and downhill portions of the road test. Among the 8 adapter blocks, the maximum load of about $14.5 \mathrm{kN}$ was recorded for BR2 in this test (Figure 8(c)).

4) Stage 4 Driving Experiment (Test 4)

For test 4, the greatest loads were recorded for BL2 during the U-turn and for BR1, BL1 and BR2 for the restart. Among the 8 adapter blocks, the maximum load of about $16 \mathrm{kN}$ was shown experienced by BL2 (Figure $8(d))$.

The results of the analysis of the four driving experimental runs, test 1 - test 4 , revealed that a maximum load of $15 \mathrm{kN}$ was applied on adapter block type A and a maximum load of $25 \mathrm{kN}$ on adapter block type B. These loads were recorded at the points in the road test when the low-bed trailer was driving through unstable sections of the test such as stopping, restarting, passing over a speed bump or taking a left turn at speed. The simulations performed by Park et al. [6] predicted the yield load of adapter block A to be about $24.6 \mathrm{kN}$ and that for adapter block B about $28.5 \mathrm{kN}$. As the maximum loads measured here were recorded when the vehicle was moving fairly rapidly through unstable sections of the test route, it seems likely that loads considerably below the yield load will be experienced by the adapter blocks when the vehicle is consistently moving at a reasonable speed throughout, as would be the case for an actual modular unit delivery operation.

\section{Conclusions}

Modular unit systems are an eco-friendly advanced construction method that improves productivity, and reduces carbon emissions and construction waste, among other benefits. However, it is important to maintain a high prefabrication ratio for the modular units in order to ensure their green building credentials. The existing method of 


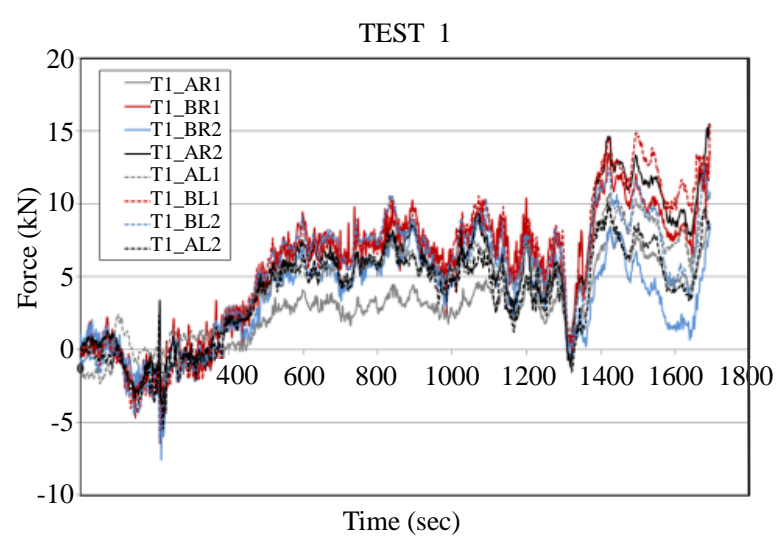

(a)

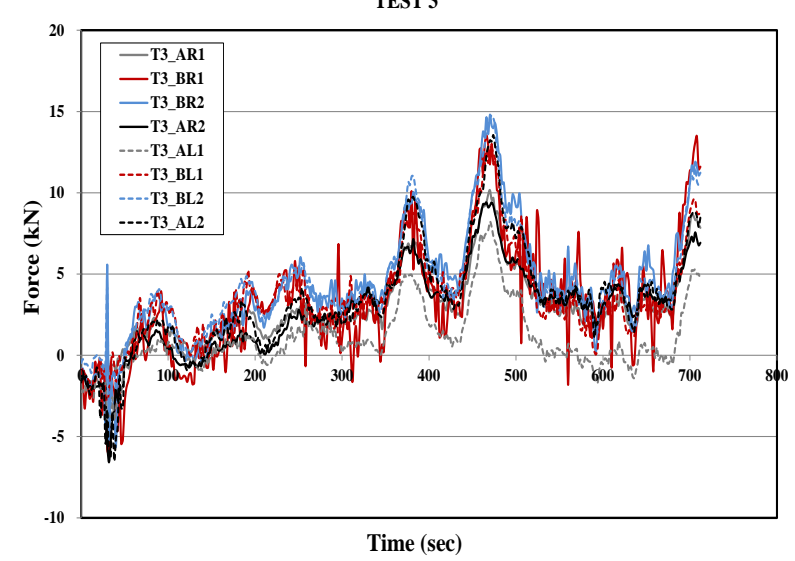

(c)

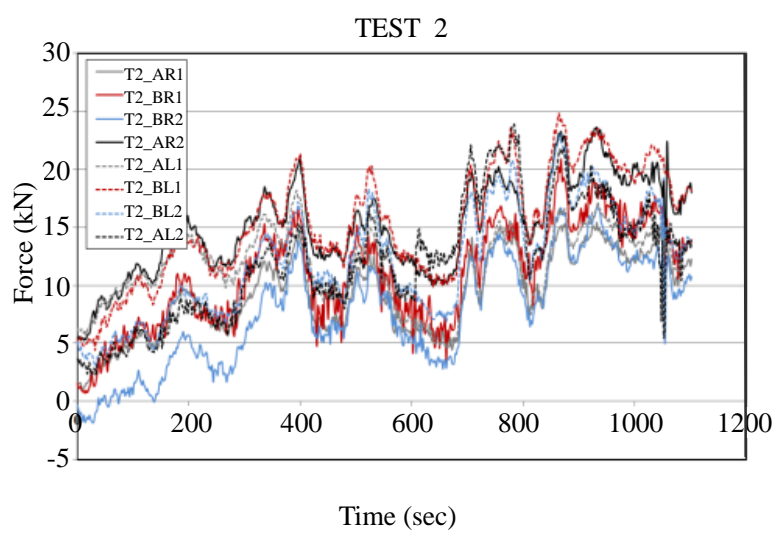

(b)

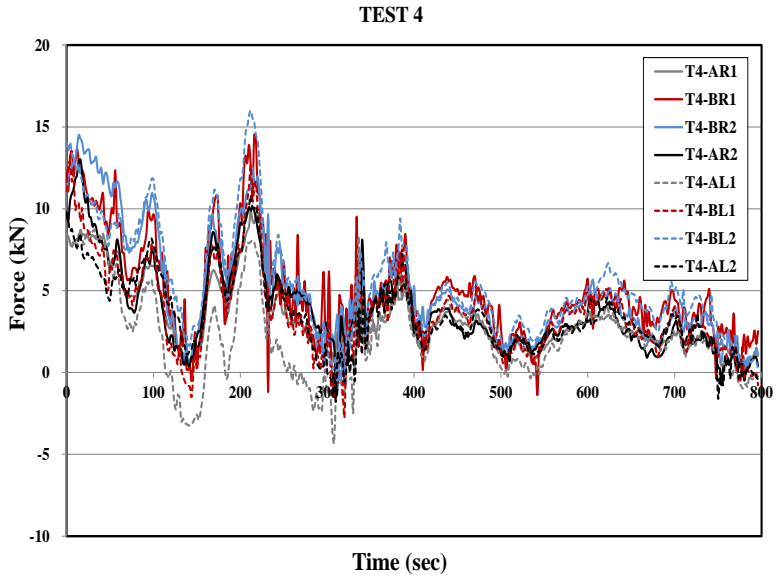

(d)

Figure 8. Strain gage readings for the driving experiment. (a) test 1; (b) test 2; (c) test 3; (d) test 4.

transporting modules to the site by fixing them onto the truck using ropes and belts is somewhat ad hoc and may damage high prefab ratio modular units, adversely affecting the eco-friendliness and productivity of this new building approach.

This study was designed to address this issue by verifying the convenience and utility of fixing modular units with high prefabrication ratio to transporting vehicles using the two adapter block styles, type A and type B, suggested by Park et al. [6]. Driving tests were also conducted to confirm their roadworthiness and safety.

Prototype adapter blocks were manufactured and shown to experts familiar with the modular unit system approach to solicit their opinions of the proposed experimental tests. Based on their advice, the driving experiment was modified by reinforcing the adapter blocks and a low-bed trailer used to ensure the safe performance of the experiment. The experts also recommended simplifying the handling procedure required. The experienced driver who participated in the road tests was also asked to evaluate the ease of using each of the two adapter block styles tested and expressed a preference for adapter block type B as it was simpler to attach and did not require additional tools.

The driving experiments revealed a maximum load of $15 \mathrm{kN}$ experienced by adapter block type A and $25 \mathrm{kN}$ by adapter block type B. Not surprisingly, the highest loads were recorded when the low-bed trailer was driving through unstable sections of the test such as stopping, restarting, passing over a speed bump or taking a left turn at speed. These values are well below the yield loads predicted by Park et al.'s [6] simulations, which were in the region of $24.6 \mathrm{kN}$ and $28.5 \mathrm{kN}$ for adapter block types A and B, respectively. This confirms that loads that are considerably lower than the yield load would be applied on the adapter blocks in the case of driving at a regular speed, so the new adapter blocks appear to offer a good option for transporting modular units with high prefab ratios. The ability to transport modules with high prefab ratios without incurring damage during transit is expected to contribute to the eco-friendliness and the improved productivity of modular unit systems. 
As this study evaluated the roadworthiness and safety of the new fixing procedure by performing driving experiments along a selected road section, there are some limitations in that the results may vary depending on road conditions, driving speed and driving habits. Also, the necessity of having to make further improvements to the adapter blocks by boosting the safety ratio and making them more convenient for workers to use must be taken into consideration. However, if appropriate improvements to the adapter blocks are achieved and tested through additional research, we confidently expect that the new adapter blocks will greatly facilitate the transportation of modular units with high prefab ratios to the site, making the entire operation both safer and more convenient.

\section{Acknowledgements}

This paper was supported by the Korea Institute of Construction Technology under the Strategic Research Project (Construction Technology Development for One-day Housing). This paper developed the Korea patent [Apparatus for fixing freight of vehicle, Korean patent, 10-1149599, 2012.05.17.] which was the result of the research.

\section{References}

[1] Kim, K.T., Chae, M.J., Park, N.C. and Park, S.Y. (2013) Development of Construction Technologies for One Day Housing. Strategy Project Report of KICT, Ilsan (Korea), December 2013, 1-104.

[2] Lim, S.H., Park, K.S., Chae, C.U. and Kwon, B.M. (2007) A Study on Factory Production of Modular Unit Housing Systems in Korea, United States, Japan, Europe. Journal of the Korean Housing Association, 8, 27-35.

[3] Song, Y.H., Lim, S.H., Lee, G.K. and Lee, W.H. (2011) A Study of the Current State Status of Prefab Architecture and Manufacturers. Proceedings of the Architectural Institute of Korea, Gyeongsan (Korea), October 2011, 65-66.

[4] Kim, K.T., Kim, S., Park, N.C. and Lee, Y.R. (2014) Development of Fixing Equipment for Transporting Modular Units. Proceedings of the Korean Institute for Structural Maintenance and Inspection, Jeju (Korea) October 2014, 709-710.

[5] Park, S.Y., Kim, K.T., Park, N.C. and Chung, I.S. (2012) Study of Improved Transportation Methods for Modular Units. Proceedings of the Korean Institute of Building Construction (Industry), Ansan (Korea), November 2012, 243244.

[6] Park, S.Y., Kim, K.T. and Park, N.C. (2013) Development and Evaluation of Fixation Equipment for Transporting Modular Units. Journal of the Korean Institute of Building Construction, 13, 609-618.

[7] Lee, K.B., Lim, K.R., Shin, D.W. and Cha, H.S. (2011) A Proposal for Optimizing the Modular Unit System Process to Improve Efficiency in Off-Site Manufacture, Transportation and On-Site Installation. Korean Journal of Construction Engineering and Management, 12, 14-21.

[8] Kim, K.T., Jung, I.S., Park, N.C. and Park, S.Y. (2012) Development of Construction Technologies for One Day Housing. Strategy Project Report of KICT, Ilsan (Korea), December 2012, 1-104.

[9] Park, N.C., Kim, K.T. and Kim, S. (2014) Correlation Analysis of a Working Load for Transporting Modular Units. Proceedings of the Korean Institute for Structural Maintenance and Inspection, Jeju (Korea), October 2014, 628-630.

[10] Kim, K.T., Park, N.C. and Lee, Y.R. (2014) A Test of Fixation Equipment for Transporting Modular Units. Proceedings of the Architectural Institute of Korea, Busan (Korea), October 2014, 695-696. 
Scientific Research Publishing (SCIRP) is one of the largest Open Access journal publishers. It is currently publishing more than 200 open access, online, peer-reviewed journals covering a wide range of academic disciplines. SCIRP serves the worldwide academic communities and contributes to the progress and application of science with its publication.

Other selected journals from SCIRP are listed as below. Submit your manuscript to us via either submit@scirp.org or Online Submission Portal.
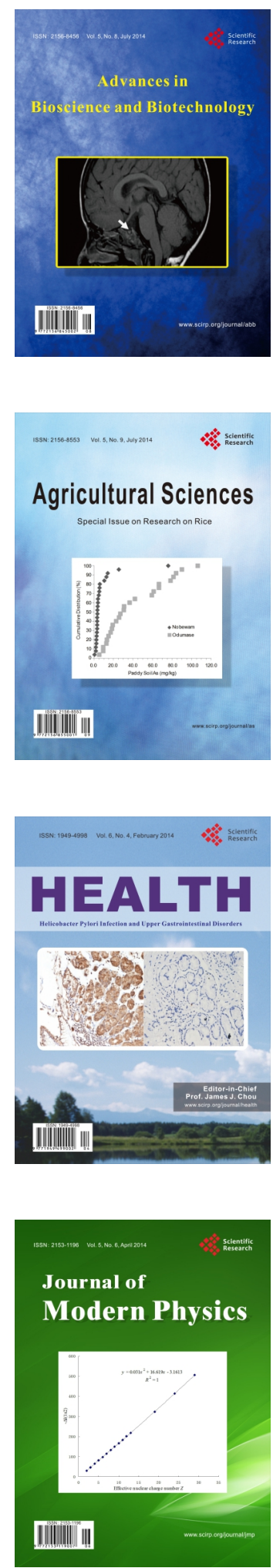
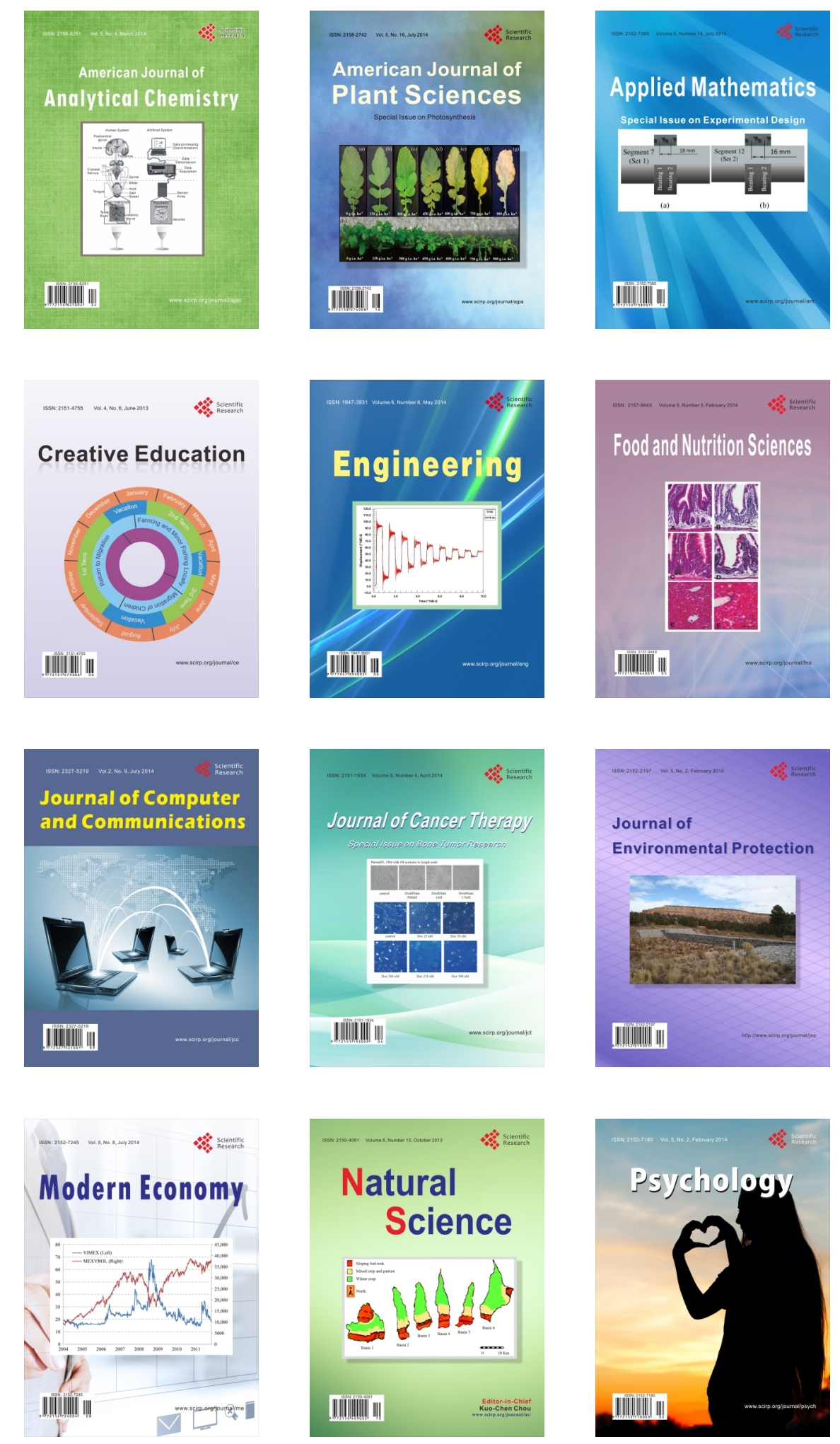